\title{
Arquitetura e suas [im]possibilidades: uma discussão a partir das análises de Manfredo Tafuri, Fredric Jameson e Rem Koolhaas.
}

\section{Architecture and its [im]possibilities: a discussion about the Manfredo Tafuri, Fredric Jameson and Rem Koolhaas's analysis.}

\section{CAROLINA MARGARIDO MOREIRA}

Arquiteta e Urbanista graduada em 2002 pela Escola de Engenharia de São Carlos, Universidade de São Paulo, atualmente mestranda pelo Programa de Pós - Graduação em Arquitetura e Urbanismo do Departamento de Arquitetura e Urbanismo da Escola de Engenharia de São Carlos da Universidade de São Paulo, na área de concentração Teoria e História da Arquitetura e do Urbanismo. Integrante do Grupo de Pesquisa Brasil, Arte e Arquitetura: diálogos na cidade moderna e contemporânea, cadastrado no CNPq desde março de 2006.

carolinamargarido@uol.com.br

\section{Resumo}

As contradições que o processo de conformação das cidades contemporâneas como um todo gera e que questiona a própria arquitetura e, conseqüentemente, o entendimento da realização do construir como contradição tornou-se essencial.

Aprofundar a forma como é trabalhada a compreensão de aspectos de configuração da forma urbana tais como contexto, processo e produto; assim como ampliar a compreensão de distintos processos de espacialização da cidade, enfatizando o estudo de sua evolução teórica e aplicada, desde os fins do século XIX, é o principal objetivo ao se buscar entender inicialmente o sentido e as etapas fundamentais da história da arquitetura, da urbanística moderna e da ideologia discutida por Manfredo Tafuri.

Desta forma, a conseqüente discussão sobre a metrópole contemporânea e a "hiper - urbanização" global, realizada no presente trabalho, a partir das análises filosóficas de Fredric Jameson sobre "a lógica cultural do capitalismo tardio" e a leitura a respeito da atuação teórica e projetual de Rem Koolhaas tornam-se de suma importância, assim como o é entender o fenômeno urbano atual, visto que a questão urbana é, para Jameson, uma questão contemporânea na qual o urbanismo é a fotografia de um determinado fenômeno que reflete, assim, um fenômeno mais geral. 


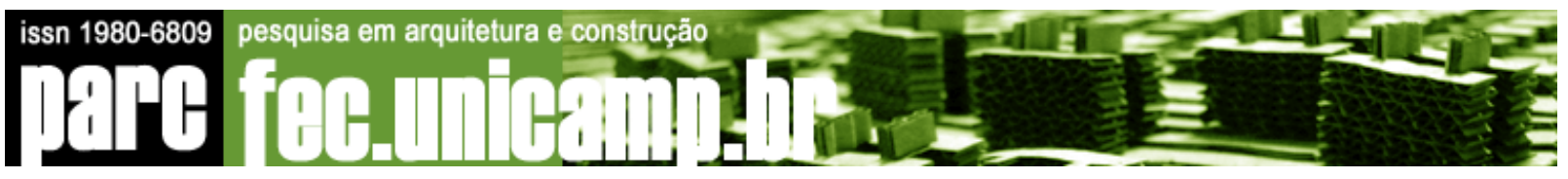

Palavras-chave: Urbanismo; Metrópole; Ideologia urbana; Rem Koolhaas; Manfredo Tafuri; Fredric Jameson.

\section{Abstract}

The contradictions that the process of conformation of the contemporaneous cities as a whole generate and that inquire the architecture itself and, consequently, the understanding of the accomplishment of building as a contradiction has become essential.

Deepening the way that the comprehension of aspects of configuration of the urban form such as context, process and product, is worked; and amplifying the comprehension of distinct processes of the city' spaciousness, emphasizing the study of its theoretical and applied evolution, since the end of the nineteenth century, are the main objectives in the search for the understanding initially the sense and the fundamental stages of the architecture's history, of the modern urbanity and of the ideology discussed by Manfredo Tafuri.

In this sense, the consequent discussion about the contemporary metropolis and the global "hyper urbanization", proposed in this paper, through the Fredric Jameson's philosophical analysis about "the cultural logic of the late capitalism" and the reading related to the theoretical and practical actuation of Rem Koolhaas become extremely important, as the understanding of the present urban phenomenon, since the urban issue is, for Jameson, a contemporary question in which urbanism is the photography of a determinate phenomenon that reflects, thus, a more general phenomenon.

Key-words: Urbanism; Metropolis; Urban ideology; Rem Koolhaas; Manfredo Tafuri; Fredric Jameson.

\section{Arquitetura e suas [im]possibilidades: uma discussão a partir das análises de Manfredo Tafuri, Fredric Jameson e Rem Koolhaas.}

\section{INTRODUÇÃO}

Observa-se hoje o desenrolar de um processo através do qual a cultura e os equipamentos culturais têm adquirido papel cada vez mais central, facilmente observado nas práticas das chamadas políticas públicas urbanas que caracterizam as ações do Estado, nos seus vários níveis, e de seus parceiros preferenciais, nas intervenções dos espaços urbanos da cidade contemporânea.

Os princípios que conduzem tais práticas, suas diretrizes e, principalmente, a forma com que o conjunto de relações sociais, econômicas, políticas e culturais transforma e modela os 
ambientes urbanos e o imaginário dos habitantes a partir da ação de um complexo campo de forças, exigem uma reflexão que torne possível construir um entendimento da totalidade resultante dessas múltiplas relações e, assim, uma melhor compreensão dos processos de conformação das cidades contemporâneas como um todo.

Para tanto, entender as contradições que esse processo gera e que questiona a própria arquitetura e, conseqüentemente, a realização do construir como contradição tornou-se essencial. Aprofundar a forma como é trabalhada a compreensão de aspectos de configuração da forma urbana tais como contexto, processo e produto; assim como ampliar a compreensão de distintos processos de espacialização da cidade, enfatizando o estudo de sua evolução teórica e aplicada, desde os fins do século XIX, é o principal objetivo ao se buscar entender inicialmente o sentido e as etapas fundamentais da história da arquitetura, da urbanística moderna e da ideologia discutida por Manfredo Tafuri que, "ao procurar esclarecer as bases de sua análise, afirmando que trabalhou a ideologia: como estrutura, portanto, da falsa consciência humana", delimitou a "arquitetura como ideologia, como instituição que 'realiza' a ideologia, como disciplina posta em crise pelas novas técnicas de integração do universo produtivo e da planificação anticíclica..." Ajustando esta conceituação em relação à vanguarda moderna, afirmou: "A sua crise só sobrevém no momento preciso em que, perante a realidade do Plano, se torna objetivamente obsoleto o papel de quem antecipa ou medeia ideologicamente o próprio plano". ${ }^{2}$

A partir do entendimento dessa discussão de uma ideologia urbana moderna realizada por Tafuri, a conseqüente discussão sobre a metrópole contemporânea e a "hiper - urbanização" global realizada a partir das análises filosóficas de Fredric Jameson sobre "a lógica cultural do capitalismo tardio" e a leitura a respeito da atuação teórica e projetual de Rem Koolhaas tornam-se de suma importância para entender a transformação da cidade e da arquitetura, assim como para entender o fenômeno urbano no mundo contemporâneo visto que a questão urbana é, para Jameson, uma questão contemporânea na qual o urbanismo é a fotografia de um fenômeno que reflete um fenômeno mais geral.

A partir dessa condição surgem, então, as questões atuais acerca da cidade e da relação do homem com o mundo, conformando-o e, ao mesmo tempo, sendo por ele conformado. Observa-se, portanto, a construção de um olhar advindo com a chamada "pós-modernidade" mesmo que esta já não seja pertinente - a partir da modernidade que evita um julgamento moral do pós-moderno e de sua celebração, ao mesmo tempo em que se percebe que,

\footnotetext{
1 TAFURI, M. Projeto e Utopia. Pg. 13.

2 Idem. Pg.14.
} 


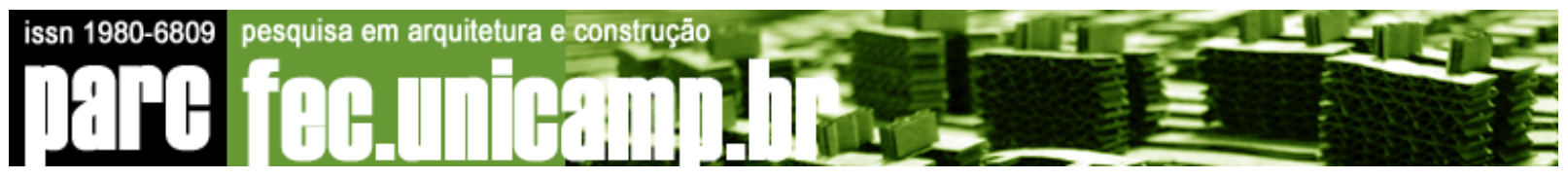

devido à inserção nessa realidade, tal análise constitui uma postura basicamente política por parte de seus autores.

Segundo Jameson, é na arquitetura que se verifica mais evidentemente as transformações da produção estética e seus problemas teóricos: nesse âmbito, o alto modernismo - como ele denomina - foi criticado por ignorar e até mesmo destruir tanto as antigas culturas quanto a forma urbana com que a cidade tradicional se configurou, ao mesmo tempo em que, para Jameson, um forte elitismo e autoritarismo são facilmente identificados em suas aplicações teóricas. De forma contrária, a arquitetura pós - moderna, segundo esta teoria, ao deixar de separar a alta cultura e a chamada cultura de massa ou comercial, possibilita a existência de um espaço no qual as diferenças da nova sociedade, a "sociedade pós-industrial, de consumo, das mídias, da informação, sociedade eletrônica ou high-tech", podem ser externalizadas. As teorias do pós-moderno demonstram, então, uma nova formação social, "que não mais obedece às leis do capitalismo clássico, a saber, o primado da produção industrial e a onipresença da luta de classes."3 0 pós-modernismo na cultura está, segundo as análises de Jameson, diretamente ligado a um posicionamento político com respeito à natureza do capitalismo multinacional em nossos dias.

Por todas essas questões, pode-se concluir que uma periodização histórica pode acabar funcionando como um nivelador, excluindo as diferenças e mostrando um período histórico como uma massa homogênea de idéias e acontecimentos, cujo ápice é uma brusca transformação que antecede outro período de igual homogeneidade e assim por diante.

Enfim, o presente trabalho, é de suma importância para o desenvolvimento de uma leitura crítica sobre as intervenções atuais na área central de São Paulo, e suas relações com os equipamentos culturais nela existentes ou implantados. Especificamente pelo interesse nas questões levantadas pelos autores estudados relativas aos aspectos de caracterização do espaço urbano contemporâneo, a busca por um resignificado dos conhecimentos e ações da arquitetura na dimensão territorial urbana foi o principal objetivo deste.

\section{INOVAÇÃO X TOTALIDADE: O FIM DA DIALÉTICA MODERNA E A OBRA DE REM KOOLHAAS}

"As cidades hoje, a cidade que temos que enfrentar, são feitas de fragmentos, pedaços de modernidade."

Rem Koolhaas

\footnotetext{
${ }^{3}$ TAFURI, M. Projeto e Utopia. Pg. 29.
} 
Muitos aspectos da ideologia urbana moderna discutidos e analisados por Tafuri são trabalhados por Koolhaas, não em termos de um projeto cultural ou social unitário, em certo sentido utópico, mas em termos arquitetônicos que expressem uma única linguagem, ou uma única narrativa - mesmo porque para Koolhaas, acompanhando toda uma literatura cultural contemporânea, deixou de ser pertinente 'a' ou 'uma' narrativa em um nível ideológico, ou melhor, heterológico e heterotópico - partindo da constatação da coexistência de distintas narrativas no mundo contemporâneo e da necessidade de mostrá-las.

Portanto, é interessante observar a maneira com que Koolhaas, como arquiteto e teórico, se posiciona em relação à dialética moderna "Inovação x Totalidade": embora não haja a preocupação com a forma no sentido moderno - mesmo que Koolhaas considere a estética das estruturas modernas atrativas, positivas - há ainda uma busca pelo alcance da totalidade, na qual todas as partes estão em relação formal com o todo.

O fim da dialética moderna entre inovação e totalidade é uma constatação que Jameson observa em Koolhaas, que a utiliza em praticamente todos os seus projetos, assim como o fim da utilização da determinação como meio de leitura e atuação na metrópole. Interessante notar que a indeterminação como única determinação possível para o conjunto urbano já é detectada por Tafuri, que a relaciona ao fracasso da urbanística moderna apoiada na forma enquanto tentativa utópica de controle.

Em relação à forma e sua desagregação, Koolhaas não mais entende a arquitetura como uma disciplina e não mais acredita na autonomia pregada pelo modernismo, assim como o espaço passa a ser visto por ele como articulação de elementos existentes, uma junção das "coisas" extra-arquitetônicas. A partir do momento em que o programa passa a ser mais importante que a forma, material e detalhes construtivos, este deve abranger os elementos existentes na metrópole, que passa a assumir o papel de uma segunda natureza, uma natureza tecnológica na qual o homem se dilui e desaparece, assim como era antes da separação moderna entre homem e natureza, ou sujeito e objeto, tão bem descrita nos ensaios filosóficos de Georg Simmel. ${ }^{4}$

Tal atitude pode ser analisada como uma busca pelo fim ou anulação da contradição inerente à arquitetura como parte de um processo que, ao dominar e destruir a natureza, acaba

\footnotetext{
${ }^{4}$ Ler a respeito em SIMMEL, G. "A metrópole e a vida mental", in VELHO, O. (org) - O fenômeno urbano, Rio de Janeiro, Zahar, 1967 e WAIZBORT, L. "As Aventuras de Georg Simmel”. São Paulo : Editora 34, 2000.
} 
destruindo o próprio homem e sua subjetividade, como descrito por Tafuri ao analisar a arquitetura moderna como a obra de arte da neovanguarda, que se espelha na metrópole contemporânea ao construir espaços ou objetos arquitetônicos que se configuram como fragmentos incompletos.

De acordo com essa análise, as novas propostas de resgate da arte assumiram as mesmas feições das propostas das vanguardas históricas, mas, segundo Tafuri, sem "a clareza ou confiança em si mesmas que aquelas podiam legitimamente ostentar", ou seja, sem a preocupação social das anteriores. Para James Rosenquist, a obra de arte da neovanguarda, cada vez mais "baseada nos fragmentos incompletos que propiciam a experimentação de uma nostalgia romântica, tem muito a ver com idéia de colecionismo de uma pessoa que compra um testemunho do tempo e da história". A arquitetura ou os objetos arquitetônicos, então, poderiam também ser vistos como a obra de arte, como um "fugaz fluxo de movimentos estáticos".

A arquitetura passa assim, para Tafuri, a ser caracterizada pelo vazio formal e pelos significado que, como fragmentos, assumem na metrópole contemporânea. Segundo ele, "para reger o espaço metropolitano a arquitetura parece obrigada a tornar-se o fantasma de si própria com a pretensão de definir - unicamente com os instrumentos disciplinares que lhe são próprios - as estruturas primárias da cidade". ${ }^{6}$ Assim, a idéia de fragmento de Tafuri é muito importante: se as idéias da vanguarda, ou o projeto moderno, já não podem ser aplicados na sua totalidade, resta a aplicação de fragmentos. Desta forma, cada agrupamento artístico ou arquitetônico dedica-se à fragmentos do modernismo: a técnica [high-tech], o desenvolvimento formal [neovanguardas] etc, sendo evidente que o fragmento não se realiza sem problemas ou sem diferenças, já que um pedaço no todo é distinto do mesmo pedaço sem o todo.

Como a forma era, assim, vista como oposição ao caos - devendo ser procurada dentro dele - a reconquista da totalidade do ser ou da arte estava condicionada à problematicidade da própria forma, que traduziria esse mesmo caos em ordem e liberdade. O conceito de totalização foi utilizado, contudo, com o intuito de racionalizar a organização global da "máquina citadina" moderna, que deveria constituir uma "imagem unitária" na qual coexistiriam o rigor do plano - a necessidade - e a liberdade.

\footnotetext{
${ }^{5}$ TAFURI,M. Projeto e Utopia. Pg. 96.

${ }^{6}$ Mies Van der Rohe - que segundo Tafuri teria tido várias fases, iniciando em uma cultura antiutópica e seria o enfant terrible do movimento moderno - profetizou algo que se tornou realidade experimentada nas cidades norteamericanas: seus edifícios transformaram-se em objetos capazes de "existir através da própria morte, só assim se salvando de um naufrágio certo", caracterizando bem essa transformação da arquitetura. TAFURI, M. Projeto e Utopia. Pg. 98.
} 
Já Koolhaas, acreditando que resistir à totalização resulta apenas em uma falsificação das diferenças, visto que tudo nunca foi tão homogêneo como hoje - a defesa das diferenças só surge a partir do momento em que ela não mais existe - "a abraçou com entusiasmo" ... "dando corpo à vontade de incluir um mundo inteiro dentro de i" $^{7}$, ao contrário dos modernos, que viam na homogeneização a igualdade e a padronização necessárias em função da adoção de métodos racionais, não existentes nas cidades: as Siedlungen se contrapunham à realidade existente, e por isso tinham que ficar "fora" das cidades, sendo seu oposto, já que a metrópole, por ser "naturalmente" contraditória e desordenada, não aceitaria o equilíbrio inerente à organização destas.

De acordo com Tafuri, do elemento padronizado à célula, ao bloco singular, à Siedlung, à cidade: esta foi a cadeia de montagem implantada com excepcional clareza e coerência pela cultura arquitetônica de entre as duas guerras. Nela, cada pedaço é completamente resolvido em si e tende a desaparecer, a diluir-se formalmente na montagem. Acontece assim, uma revolução da própria experiência estética: não se trata mais da apreciação de objetos, mas sim de um processo, a viver e a fruir enquanto tal.

\subsection{O CONCEITO DE BIGNESS OU URBANIDADE INTERIOR}

Relativo a esse princípio da Totalidade e, de certa forma, à crise da função ideológica da arquitetura, o conceito do "Bigness" ou "Urbanidade interior", desenvolvido por Koolhaas, coloca que o tamanho do edifício como o instigador de um programa ideológico que independente do desejo de seus arquitetos não é um problema intelectual - considerado por Koolhaas como a caminho da extinção: tal conceito instiga ainda o regime da complexidade que mobiliza toda a inteligência da arquitetura e de seus campos relatados. Proporcionado pelas invenções tecnológicas, o conceito do Bigness praticamente reorganiza o mundo social de acordo com uma muito vasta programação, em uma condição livre dos pensadores, ou seja, uma condição completamente oposta à existente na ideologia urbana moderna.

O interessante é a forma pela qual o Bigness decorre da constatação de uma impossibilidade de comandar ou controlar da arquitetura: a autonomia das partes não é vista como fragmentação, mas como uma espécie de "antídoto" contra ela, visto que as partes permanecem comprometidas com o todo. Segundo Koolhaas, os projetos de grande escala "exigem a adoção de uma postura crítica diante das imposições da tecnologia tanto em matéria de

\footnotetext{
7 JAMESON, F. Os limites do pós-modernismo. Pg 178.
} 
estrutura como de instalações. Um outro ponto é que têm um caráter cultural relativo à sua condição de universo autocontido - com todas as liberdades, atrações e singularidades que isto implica". ${ }^{8}$

Em decorrência do Bigness, surge a necessidade de se imaginar uma nova forma na qual estes universos independentes e não-complementares possam coexistir, talvez realizando a crítica da própria ideologia através de uma eliminação dos "mitos impotentes e ineficazes a que recorriam as esperanças projetistas anacrônicas", a qual Tafuri se referia ao falar da possibilidade futura da atuação arquitetônica. Nesse sentido, o elevador é visto como um meio tecnológico com potencial de estabelecer conexões mecânicas mais que arquitetônicas, assim como as demais "invenções" são responsáveis por uma transformação nas relações de composição, escala, proporção e detalhes. A arte da arquitetura, portanto, torna-se praticamente inútil no Bigness, não servindo mais à dissimulação das contradições da cidade contemporânea.

Na Europa, especificamente, Bigness gera uma discussão sobre sua aplicação, tendo ainda o valor da contribuição da megaestrutura - cujo suporte técnico coloca em questão o status de um edifício individual. Para Koolhaas, isso gera um Bigness mais "saudável": ainda limitado, mas com um potencial desfocado que renova tudo mas nunca confronta, nunca exige seu lugar e, por isso, acaba sendo criticado como decoração.

Assim sendo, Bigness possibilita hibridizações programáticas, proximidades, fricções, sobreposições, superposições que detonam todo o aparato inventado no começo do século analisado por Tafuri - para organizar as relações entre partes independentes. $O$ desaparecimento transcende a questão do Bigness e de sua presença massiva através do extenso engajamento com a simulação, virtualidade e não-existência. Para Koolhaas, a experimentação da virtualidade assume o desaparecimento da arquitetura prevista pelos sociólogos, ideólogos e filósofos americanos, intelectuais franceses etc, que sugeriram a arquitetura como o primeiro "sólido que desmancharia no ar" devido aos efeitos combinados da expansão demográfica, eletrônica, da mídia, da economia, do fim da religião, do livro, do telefone, do fax, democracia, enfim, do fim da Grande História. Em nome da modéstia, "Bigness assume a onipotência do mundo da realidade virtual".

Como teórico, Koolhaas vê na arquitetura uma profissão que se torna assim incapacitada de explorar os eventos sociais e econômicos dramáticos que, se confrontados, poderiam restaurar sua credibilidade. Sem a construção de uma teoria do Bigness, os arquitetos estariam, segundo ele, se colocando na posição de "criadores de Frankensteins": investigadores de um parcial experimento bem sucedido cujos resultados estariam se perdendo e assim,

\footnotetext{
${ }^{8}$ KOOLHAAS, R. El Croquis “OMA - Rem Koolhaas 1987-1992”. Pg 20.
} 
sendo desacreditados. De acordo com Koolhaas, já que o Bigness não existe como teoria, não se sabe bem o que fazer: onde colocá-lo, como usá-lo, como implantá-lo, ou seja, segundo ele, "grandes erros são nossas únicas conexões com o Bigness". 9

Contudo, Koolhaas tem consciência de que esse é um domínio teórico do fim do século cuja atração principal é seu potencial de reconstruir o "todo", fazer ressurgir o "real", reinventar o coletivo, atraindo suas máximas possibilidades. Só através do Bigness a arquitetura poderia se dissociar dos exaustivos movimentos artísticos e ideológicos do modernismo e do mero formalismo para reaver sua instrumentalidade como veículo de modernização. Koolhaas reconhece as dificuldades inerentes à arquitetura, mas não as compensa com o que ele denomina de "regurgitações de mais arquitetura". Para tanto, propõe uma atuação na nova economia que não parte do princípio de que "tudo é arquitetura", mas do qual uma posição estratégica é baseada na concentração, produzindo o resto do "contestado território de forças inimigas".

Para tanto, o Bigness precisaria destruir para criar um novo começo, que reacenderia o que ele quebrou, que pode ser exatamente a postura que Tafuri define como ideal ao afirmar a não possibilidade de se propor "contra-espaços" arquitetônicos e da procura de alternativas inseridas nas estruturas que condicionam o próprio caráter do projeto. Para Tafuri, não há possibilidade de salvação da arte dentro da própria arte, devido ao fato desta estar situada entre os objetivos "positivos" e a desumana auto-exploração da sua redução objetiva a mercadoria, contra os quais as ideologias antiurbanas se voltaram na crise que ocorreu no início dos anos 1930, em Berlim, no terreno específico da arquitetura, e que mostrou que a diluição do objeto arquitetônico no processo formativo do conjunto chocava com as contradições do próprio movimento moderno.

Um paradoxo é que apesar de todo o cálculo necessário ao seu planejamento - devido à sua séria rigidez - Bigness depende de regimes de liberdade, da máxima diferença, para poder sustentar uma promíscua proliferação de eventos em um único container, como são chamados os espaços como Shoppings, Aeroportos, Bibliotecas, Museus etc. Através do domínio da contaminação sobre a pureza, e da quantidade sobre a qualidade, Koolhaas coloca esse conceito como um modelo de uma espécie de "alquimia programática" cuja artificialidade e complexidade defendem certo tipo de "liquefação" para poder suportar genuinamente novas relações entre entidades funcionais que expandem mais que limitam suas identidades.

\footnotetext{
${ }^{9}$ KOOLHAAS, R. "S, M, L, XL".
} 
As atividades intrínsecas à estrutura demandam a interagir, mas Bigness as mantém separadas e regula as intensidades da coexistência programática, configurando certo nível de controle intrínseco à sua proposta. Percebe-se que a dosagem de controle e liberdade é muito importante na obra de Koolhaas, e se contrapõe ao controle total buscado pela ideologia urbana moderna, mesmo que esta tenha tentado teoricamente em alguns momentos também inserir certos graus de liberdade e flexibilidade através de algumas possibilidades de escolha e participação por parte do público a qual se destinava, referente principalmente à atuação de Le Corbusier, cujos objetivos, segundo Tafuri, - no âmbito da cultura progressista européia - foram os de "absorver aquela multiplicidade, mediar o improvável com a certeza do plano, compensar a organicidade e desorganicidade agudizando-Ihes a dialética, demonstrar que o nível máximo de programação produtiva coincide com o máximo de produtividade do espírito", refletindo a consciência da frente tripla em que a arquitetura deveria combater: organização da produção, além de distribuição e consumo. Ao arquiteto, caberia ser organizador, e não "desenhador de objetos". ${ }^{10}$

$\mathrm{Na}$ escala da cidade, as malhas das grandes estruturas - ou terrains artificiels apresentavam uma liberdade de inserção de elementos residenciais pré-formados como meio de oferecer um convite para que o público se tornasse "projetista ativo da cidade", prevendo inclusive a possibilidade de inserção de elementos excêntricos e ecléticos nas malhas de estrutura fixa: a arquitetura foi assim utilizada como ato pedagógico e instrumento de integração coletiva. O público foi, então, solicitado e tornado participante crítico do seu papel criativo ao contribuir para a reorganização urbana e esse foi, enfim, o papel da vanguarda industrial, da autoridade, dos "fruidores", uma função praticamente homogênea no processo de contínuo desenvolvimento e transformação. ${ }^{11}$

Contudo, o que diferencia o tipo de controle das ideologias citadas é que o tipo de controle proposto pela teoria do Bigness, ao mesmo tempo em que estimula a intensidade, oferece também graus de serenidade e brandura devido ao fato de ser, segundo Koolhaas, simplesmente impossível "animar" sua massa inteira com intenção. A partir dessa postura, vastidão do Bigness exausta, assim, a compulsão arquitetônica por decidir e determinar e, para controlar essa exaustão, zonas são deixadas de lado, como se estivessem "livres" da arquitetura.

\footnotetext{
${ }^{10}$ TAFURI,M. Projeto e Utopia. Pg. 86.

${ }^{11}$ Idem. Pg. 90.
} 
Dessa forma, controle e liberdade são cuidadosamente dosados e a arquitetura se torna, ao mesmo tempo, mais e menos arquitetônica: mais por causa da enormidade do objeto; menos por causa da perda da autonomia, que desaparece enquanto disciplina que tem um repertório próprio: ela se torna, assim, instrumento de outras forças, das quais é também dependente. Essa ambição arquitetônica pela megalomania só se torna passível de alcance ao preço de desistir de controlar e, justamente por isso, a força a estabelecer uma relação direta com outras disciplinas tão críticas quanto a arquitetura, montando uma espécie de "equipe", ou Team, como Koolhaas define.

Para a ideologia urbana moderna, contudo, essa liberdade estaria mais relacionada com um convite para que o público se tornasse "projetista ativo da cidade", utilizando a arquitetura como ato pedagógico e instrumento de integração coletiva, o que não deixa de ser também uma forma de controle.

Interessante comparar também o valor do vazio para a teoria do Bigness e para a ideologia urbana moderna: para Koolhaas, o vazio é o único elemento de controle, já que o edifício está sempre sujeito às forças políticas, financeiras e culturais - em transformação perpétua e, portanto, incontroláveis como as áreas e formas de aglomeração -, enquanto o vazio é o sujeito onde as certezas arquitetônicas são ainda convincentes ${ }^{12}$. Para a ideologia urbana moderna, o vazio é o lugar onde as abstrações arquitetônicas se realizam, fora da contingência da realidade, do caos: daí surge a necessidade da "terra arrasada".

Koolhaas determina então - segundo esse princípio de "void and full" ou "nothingness" - "zonas de liberdade" para as construções, onde as leis de arquitetura ficam suspensas, e determina as zonas de controle, ou seja, o "vazio" onde fica determinada a não construção. Para a ideologia urbana moderna, segundo Tafuri, o espaço vazio é apenas mais um elemento constitutivo da edificação pois, ao formar quarteirões, torna-se fator de configuração urbana e, portanto, objeto de controle e ordenação, como qualquer outro.

Segundo Tafuri, "a arquitetura da grande cidade depende essencialmente da solução dada a dois fatores: a célula elementar e o conjunto do organismo urbano". De acordo com essa visão, a importância de cada espaço - ou pedaço da cidade - para o todo caracteriza o espaço vazio, por exemplo, como elemento constitutivo da habitação determinando-lhe o aspecto que, ao formar os quarteirões, o vazio torna-se um fator de configuração urbana, aquilo que

\footnotetext{
${ }^{12}$ Segundo Koolhaas, se quisermos usar o vazio, a paisagem, como espaço para criar um lugar, este se tornará uma missão para muitos seguidores, o que não acontece ao trabalho de arquitetura, que hoje está localizado, a priori, pela desconfiança e descrença. QUADERNS Monografies. Pg. 32.
} 
"representa a verdadeira finalidade da arquitetura; reciprocamente, a estrutura planimétrica da cidade terá uma influência substancial no projeto da habitação e do espaço vazio". ${ }^{13}$

Para a cidade, as conseqüências do Bigness é que ele transforma a arquitetura, e sua acumulação gera um novo tipo de cidade: o "exterior" da cidade não é mais um teatro coletivo onde isso acontece; não há um coletivo "abandonado" como, por exemplo, a rua, que tem se tornado, para Koolhaas, um resíduo organizacional, um "mero segmento no plano metropolitano contínuo". Bigness pode existir em qualquer lugar do plano e, apesar de incapaz de estabelecer relações estáveis com a cidade clássica - enfim, ele apenas coexiste -, a quantidade e complexidade das facilidades que ele oferece para tanto, o faz urbano.

A grande cidade não é, portanto, mais vista como uma verdadeira unidade, como uma "enorme máquina social", mas o Bigness, assim como a "célula moderna", pode ser visto como o elemento que condiciona a dinâmica de outras - mas não todas, como no caso moderno construções da cidade. Em relação à possibilidade de passar a ter o valor de tipo moderno, ao contrário deste, Bigness não predispõe todas as coordenadas de planificação do conjunto urbano, não propõe que cada pedaço da cidade seja completamente resolvido em si, assim como também não pretende se diluir na homogeneidade da cidade de forma a transformar o caos nela existente em forma lógica e unívoca.

Segundo Koolhaas, isso não acontece justamente porque Bigness não apenas precisa da cidade, ele compete com a cidade, representa a cidade, pressupõe a cidade, "ele é a cidade": se o urbanismo gera o potencial que a arquitetura explora, Bigness enfatiza a "generosidade" do urbanismo acima dos significados da arquitetura e, justamente devido a sua total independência do contexto, é a única arquitetura que pode sobreviver, mesmo exportar, a atual condição global da "tabula rasa": não se inspira pelos dados dos sentidos passados, mas gravita oportunisticamente para locais de máxima promessa estrutural, o que o difere completamente dos métodos generalizáveis e da planificação urbanística de Le Corbusier, por exemplo.

Koolhaas coloca ainda que nem toda a arquitetura, nem todo o programa e nem todos os eventos serão atingidos pelo Bigness: há muitas necessidades com as quais ele simplesmente não tem nada a fazer justamente por serem muito enfocadas, fortes, desafiantes, secretas, subversivas. Bigness é o último grau da arquitetura: uma contradição, uma hiper-arquitetura, e seus containers serão, para ele, os dominantes na paisagem pósarquitetural: inflexíveis, imutáveis, definitivos.

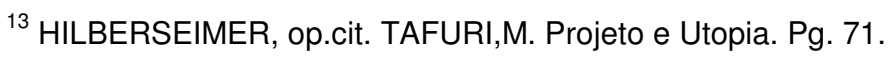


Mais além, a "vontade de incluir um mundo inteiro dentro de si", identificada por Jameson nos projetos de Koolhaas é um grande contraponto ao projeto moderno: "essas aventuras públicas devem sublinhar a exclusão da vida privada" quando consideram que não existe mais lugar para a experiência histórica e geográfica devido à identificação de um processo de reificação da vida social. Sendo assim, "os paradoxos da propriedade privada depois do fim da sociedade civil'14 são reincorporados ao projeto.

As categorias modernistas mais antigas de envoltório, incorporação, recipiente e a dualidade entre interior e exterior são, desta forma, exacerbadas e denotam a não existência de uma modernidade em si, e nem de uma pós-modernidade em si, já que uma só existe em relação à outra. Segundo Jameson, "a caixa enorme que aloja a Biblioteca da França ${ }^{15}$, por exemplo, contraria, por sua própria enormidade, as concepções tradicionais da parte externa ou da forma". ${ }^{6}$

Essa não-forma "negaria as concepções mais grandiosas, corbuseanas, da relação essencialmente expressiva entre o interior e suas linhas plásticas e paredes exteriores que abandonam suas rigidez e acompanham flexivelmente suas funções de forma a corresponder esteticamente às realidades tão diferentes do interior"17 constituindo, assim, o que Jameson denomina estética hemenêutica: cabe aos diferentes materiais utilizados nas superfícies exteriores a diferenciação das atividades espaciais e existenciais do interior do edifício, gerando o que é por ele caracterizado como uma "correspondência expressiva virtualmente pré-alegórica ou simbólica, de uma espécie de combinação um a um na qual o problema da própria representação parece desaparecer, deixando-nos com o frescor de uma espécie de natureza nova", que remeteria justamente a essa segunda natureza que o homem passa a querer imitar, num processo mimético idêntico ao que legitimou sua atuação moderna frente a essa questão.

Ainda em relação ao Bigness, a grande distância entre seu centro e os limites do edifício condiciona um ponto em que fachada não pode mais revelar o que acontece dentro: assim sendo, para Koolhaas, aquela "humanista expectativa de honestidade moderna é domada". Interior e exterior tornam-se projetos separados, um duelando com a instabilidade da programática e iconográfica necessidades, o outro - o novo agente da desinformação - oferecendo à cidade uma aparente estabilidade do objeto.

\footnotetext{
14 JAMESON, F. Os limites do pós-modernismo. Pg 179.

15 "The ambition of this Project is to rid architecture of responsibilities it can no longer sustain and to explore this new freedom aggressively. It suggest that, liberated from its former obligations, architecture's last function will be the creation of the symbolic spaces that accommodate the persistent desire for collectivity." A respeito Projeto da "Bibliothèque de France" OMA - Office for Metropolitan Architecture . KOOLHAAS, R. S,M,L,XL.

16 JAMESON, F. Os limites do pós-modernismo. Pg 179.

17 Idem. Pg. 180.
} 
Assim sendo, Bigness transforma a cidade de uma soma de certezas a uma acumulação de mistérios a partir do momento em que o que se vê não é o que se tem realmente. Seu impacto é independente de sua qualidade e sua existência não faz parte, portanto, de nenhuma questão urbana: ele apenas coexiste com os diversos elementos da cidade não pretendendo transformá-la, ou mesmo revolucioná-la, ao contrário da ideologia urbana que Tafuri analisa.

Jameson analisa o conceito Bigness - ou grande escala - de Koolhaas comparando a forma como este organiza as funções programáticas internas do edifício da Biblioteca da França (FIG. 1) a "órgãos flutuantes que pairam dentro de seu recipiente" ou, no caso, dentro do cubo imenso e translúcido dotado de uma espécie de raio-x. O conceito de "void" - nulo, vazio - é bastante utilizado na constituição dos espaços públicos internos ao edifício em que estes, segundo o próprio Koolhaas, "são definidos como ausências de edifícios, vazios escavados para fora do cubo sólido. Flutuando na memória, eles são como embriões múltiplos, cada um com sua própria placenta tecnológica". ${ }^{18}$

Aqui se identifica também uma importante postura relativa à coexistência, bastante debatida nas obras de Koolhaas, que preconiza as diferenças e considera que elas devem coexistir em uma simultaneidade "extremamente espacial" que, ultrapassando o sentido orgânico tradicional, coloca como necessária a permanência da multiplicidade e que, por isso, implica nova concepção da relação entre seus itens individuais que para os modernos eram, segundo Jameson, "figuras no chão, ou conjuntos artística e harmoniosamente combinados e construídos". Koolhaas utiliza essa "flutuação" como uma "ausência radical de chão, sem mencionar o fim de concepções ainda mais tradicionais de perspectiva, imbricação, contraste engenhoso, arranjo". ${ }^{19}$

$\mathrm{Na}$ Europa, contudo, Bigness assume uma especificidade por dois motivos: o primeiro é por sua não contextualização em um lugar em que contexto possui um significado muito forte, o segundo justamente por sua grande escala num local onde tudo é pequeno. Koolhaas interpreta, assim, tamanho e localização como sintomáticos da aparição de uma nova escala na Europa, confrontando suas cidades não tanto com o dilema - para ou contra 0 modernismo - mas com a manifestação de mais uma onda de modernização e concentração que, enquanto potencialmente terminal, era também uma condição para sua sobrevivência.

Em relação ao urbanismo moderno, Koolhaas critica aspectos como a monotonia e a irresponsabilidade devido a não atenção dada às particularidades dos diferentes contextos, e

\footnotetext{
${ }^{18}$ KOOLHAAS, R. El Croquis "OMA - Rem Koolhaas 1987-1992”. Pg 68.

19 JAMESON, F. Os limites do pós-modernismo. Pg 182.
} 
a restrição tipológica, que faz com que estas não possam se adaptadas a certos locais. Ele coloca que "no mundo contemporâneo, programas tornam-se abstratos ao tempo que não são ligados a uma cidade ou lugar específico: eles flutuam e gravitacionam de maneira oportunista em volta do lugar que oferece maiores conexões. Apenas a exacerbação da complexidade revela o ponto mágico onde os problemas são transformados em puro potencial'. ${ }^{20}$

\subsection{JUNKSPACE E CYBERPUNK}

Uma das discussões levantadas por Koolhaas e que Jameson aponta no texto Future City ${ }^{21}$ é em relação aos seus estudos sobre os Shoppings Centers, assim como a sua relação com a cidade contemporânea e sua conseqüente contribuição para o possível surgimento de um novo tipo de espaço - um espaço controlado, ou "junkspace" - e tudo o que tal fenômeno implica para a psique humana e para a própria realidade.

Jameson enfatiza a amplitude de disciplinas heterogêneas que Koolhaas mobiliza para esse tipo de análise, das quais as mais óbvias são arquitetura e urbanismo, mas que incluem também outras como psicanálise e geografia, história e administração, economia e engenharia, biologia, ecologia, feminismo etc. Apesar de a não-diferenciação ser caracterizada como a lei da era pós-moderna, a noção dessa abrangência multidisciplinar é necessária para atender aos interesses de ambos ao tentarem entender como estas se sobrepõem e como escapam aos limites que lhe foram anteriormente fixados.

Enfim, no mundo contemporâneo, a distinção entre as velhas especializações disciplinares é ultrapassada, e estas passam a se relacionar umas com as outras nos mais interessantes estudos, nos quais inclusive os Shoppings aparecem como um marco espacial e arquitetônico desse imenso tópico devido ao fato de que poucas formas têm sido, para Jameson, tão distintivamente novas e tão distintivamente americanas, e tardo-capitalistas com sua inovação, datada em 1956 - além do fato que sua proliferação pelo mundo todo poder servir como um mapa epidêmico da americanização, ou pós-modernização, ou globalização. Dessa forma, tal comparação entre essas áreas no mundo todo ajudam a visualizar uma figura não apenas das relativas hierarquias da globalização, mas do próprio "Shopping" que vai, em pouco tempo para Jameson, tornar-se não apenas uma questão política, mas também metafísica.

Além disso, é percebida uma realidade na qual os aeroportos, museus e a própria cidade estão se transformando em Shoppings, ao mesmo tempo em que os centros antigos dessas

\footnotetext{
${ }^{20}$ KOOLHAAS, R. "S, M, L, XL".

21 JAMESOM, F. Future city. In: New Left Review 21, May/June 2003. Pgs 65-79.
} 
cidades se tornam lojas virtuais. Assim, as "funções cívicas" tradicionais das cidades são oficialmente repassadas aos Shoppings, que passam a ser utilizados como modelos ideais de um novo urbanismo a ser seguido e implantado em qualquer lugar do mundo, caracterizando uma nova Utopia - sem dúvida de segunda mão -, inventada por Walt Disney, ou a "disneyficação"22, segundo Sharon Zukin, lembrando a crítica à artificialidade da vida urbana atual que Jean Pierre Jeudy aponta em Memórias do Social.

Para Jameson o "Junkspace" atua como um "vírus cuja proliferação é incontrolável e vai além da estandardização": antes relacionado às megaestruturas e à eternidade dessas, agora se torna independente de qualquer superestrutura devido ao fato de que sua construção passou a adquirir a leveza de uma "costura", cuja materialização é praticamente provisória e não tão importante. "Cyberpunk", outro conceito que Koolhaas utiliza em sua análise do mundo contemporâneo, parece ser uma referência ao ato de "agarrar" o momento, relacionado ao efêmero e à pseudotemporalidade que o fim da História impõe devido ao fato de que, quando conseguimos imaginar um futuro, este parece ser nada além de pura repetição do que já existe.

Para Jameson, o problema a ser resolvido seria o do fim do presente contínuo que se instaurou a partir da não mais utilização da Utopia de forma funcional, ou seja, como antecipação do futuro, assunto amplamente discutido por Tafuri ao definir como dominante nas ideologias urbanas modernas o tema de um futuro em que todo o presente seja projetado, de um domínio "racional" do futuro e, conseqüentemente, de uma eliminação do risco que este comporta.

Jameson coloca ainda como causa do problema do consumo excessivo da nossa sociedade não apenas a aparente falta de sentido da vida e a generalizada impossibilidade de satisfação, mas principalmente o esforço pela permanência de um estilo de vida construído e manipulado a partir de uma nova organização específica de desejos que oferece 0 consumismo como única forma de possibilidade e de sentido e que, na verdade, não depende de vendas para sobreviver, e para a qual o Shopping é apenas um tipo de "performance" que pode ser mantida sem dinheiro, desde que se aproprie de espaços. Em outras palavras, Junkspace tem, segundo Jameson, providenciado e servido de instrumento para a manutenção e permanência dessa condição.

\footnotetext{
${ }^{22}$ ZUKIN, S. "Aprendendo com a Disney World”. Revista Espaços e Debates, v. 23 - n. 43-44 - p. 11-27, jan/dez

2003.
} 


\section{4. "PROBLEMAS À MANEIRA DE CONCLUSÃO"}

Tanto para Jameson quanto para Koolhaas a produção de arquitetura tem proporcionado um maior entendimento e uma maior compreensão sobre as formas mais surpreendentes e secretas em que a sociedade de consumo se organiza, a partir da constatação de que a inserção da produção construtiva nos planos globais reduziu a funcionalidade do seu papel ideológico inicial. A ordem, que tanto atraía os Modernos é, para ambos, uma ilusão, assim como a aparente obrigação de lidar com ela mediante a arquitetura que, em seu sentido original, tem muito mais ligação com a liberdade.

Assim, os meios de articular o discurso em termos puramente arquitetônicos tornam-se completamente questionáveis: a indeterminação surge como único meio de combiná-lo com a especificidade arquitetônica. Por outro lado, segundo Tafuri afirma, as contradições econômicas e sociais que explodiram de modo cada vez mais acelerado no âmbito das estruturas urbanas e territoriais, parecem ter imposto um compasso de espera à reorganização capitalista. Para ele, o problema da racionalização do ordenamento urbano estava no fato de que as forças político-econômicas mostraram não estar interessadas em encontrar em si mesmas as forças e os instrumentos adequados à execução das tarefas indicadas pelas ideologias arquitetônicas do movimento moderno, enquanto as aproximações da urbanística e as ideologias do Plano "apareceram como velhos idola a vender ao desbarato a colecionadores apaixonados por armas antigas - no que emerge claramente a inefetividade da ideologia". 23

Para Koolhaas, o fato é que dependemos das condições que nos rodeiam, e é a partir dessas condições devemos fazer nossa própria reflexão - em parte intuitiva, em parte explícita para tornar claro onde exatamente se encontra o potencial dessa interpretação que gera cada projeto. Segundo ele, é dessa reflexão que depende que nossa representação - no sentido institucional, e não formal ou visual - seja positiva ou negativa, neutra ou apaixonada.

O Bigness, com toda a sua magnitude, se converte em antídoto contra essa fragmentação das grandes escalas ao exigir tanto a adoção de uma postura crítica diante das imposições da tecnologia em matéria de estrutura e instalações, quanto no momento em que seu caráter cultural na condição de um universo autocontido - com todas as liberdades, atrações e singularidades que isto implica - fica evidenciado, assim como a necessidade de se imaginar uma nova forma em que estes universos independentes e não complementares possam coexistir.

$\overline{23}$ TAFURI, M. Projeto e Utopia. Pg. 115. 
Segundo Tafuri, a crise da Ideologia do equilíbrio, sancionada pela história dos planos qüinqüenais soviéticos e pelo ensinamento fornecido pelas teorias econômicas poskeynesianas, revelou o equilíbrio também, na dinâmica territorial, como um idolum ineficaz, assim como esforços para realizar os desequilíbrios, para ligar indissoluvelmente crises e desenvolvimento, revolução tecnológica e mudanças radicais da composição orgânica do capital com uma perspectiva baseada na pacificação do ordenamento territorial não é "alternativa", mas anacrônica. De qualquer forma, não parece ser o estabelecimento de um suposto equilíbrio - e muito menos a pacificação do ordenamento territorial - o intuito de Koolhaas ao trabalhar com o conceito da coexistência.

Ao se priorizar, na Biblioteca da França por exemplo, a preocupação muito mais com organização que com a questão urbanística - vista como algo secundário e obsoleto - 0 abandono de pretensões urbanísticas através do simples feito de depositar o edifício ali enfatizou uma outra forma de lidar com a cidade que implica, de novo, mais liberdades.

A questão agora é se a arquitetura do conceito do Bigness - resultada de um determinado modo de produção que, em certo ponto, a determina - será configurada como novas tipologias ou, ao contrário, a própria natureza dos processos contemporâneos impedirá sua cristalização como simples tipo. Segundo Tafuri já analisava, no entanto, "perante a incerteza dos desenvolvimentos alternativos futuros é absurdo pretender construir modelos de decisão rígidos, que forneçam estratégias para longos períodos". ${ }^{24}$

Para Koolhaas, contudo, ao encontrar nessas liberdades processos centrífugos que resistem à concentração e conexão, o urbanismo europeu anos 1970 e 1980 introduziu fórmulas como modelos urbanos e, através da exploração de um urbanismo baseado na dissociação, desconexão, complementaridade, contraste, ruptura, deixam de entender a cidade como tecido, para concebê-la como uma mera coexistência, um conjunto de relações entre distintos objetos que quase nunca se articulam visual ou formalmente, que já não visam conexões arquitetônicas. A conexão, nesses casos, não é mais vista como algo necessário, assim como o planejamento deixa de ser relevante.

Isso tudo leva a uma revisão da profissão que passa a necessitar um enfrentamento de novas condições: com o "fim do urbanismo", para Koolhaas, poucos processos e operações que têm lugar na sociedade atual podem ser transformados em um projeto de ordenação. Em relação ao possível fim da esfera pública, da sociedade civil, do pensamento humanista e de

\footnotetext{
${ }^{24}$ TAFURI, M. Projeto e Utopia. Pg. 118.
} 
outros argumentos considerados tradicionalmente como positivos, Koolhaas não considera sua atitude ou posicionamento como sendo complacente, mas como sendo a expressão de uma mistura de "júbilo e horror, assim como uma tentativa de analisar essas emoções contraditórias; trata-se da fascinação como elemento de rendição, de entrega". ${ }^{25}$

Quanto à implicação de uma certa incapacidade de juízo e de uma carência de ideologia talvez característica dos discursos contemporâneos, Koolhaas considera que o que acontece é um "apaziguamento do juízo" e uma articulação do problemático, que faz justiça a todas as possíveis vertentes de um problema - as positivas e as negativas. Koolhaas compara a atuação de um arquiteto à de um médium: expostos às correntes, aos tropismos, às tendências que sugerem mutações, os arquitetos as pressentem antes mesmo que se convertam em juízos estabelecidos.

Exemplificando talvez uma certa atitude impositiva ou "ditatorial" do arquiteto, Koolhaas cita o projeto para Melun-Sénart, para o qual, segundo ele, o O.M.A. emitiu juízos sobre a beleza e a ausência de beleza, sobre o que deveria permanecer e o que deveria desaparecer, sobre 0 que deveria mostrar-se e o que deveria ocultar-se: "Emitimos juízos em termos de prioridades... Desde então, todos esses juízos são muito pessoais, e com objetivo de preservar a pureza e a liberdade das diversas forças que aqui estão em jogo, a questão moral é postergada até o último momento, ou ocasionalmente suspensa. Como dizem no Japão, flutua..."26

A interpretação que Koolhaas faz do Muro de Berlim, por exemplo, é muito interessante devido à maneira como ele o enxerga como um "remanescente maravilhoso de uma condição urbana" - já que nos seus cento e sessenta e cinco quilômetros de extensão o "fenômeno" ofereceu radicalmente diferentes significados, espetáculos, interpretações e realidades tornando, para ele, impossível imaginar outro recente artefato com o mesmo potencial significante, ou seja, o Muro é um bom exemplo de arquitetura, em seu sentido mais original. Segundo Koolhaas, em uma aparente abstenção de programa, o Muro - em sua relativa curta vida - provocou e sustentou um inacreditável número de eventos, comportamentos, e efeitos: apesar das rotineiras inspeções - militares no Leste e turísticas no Oeste - com um vasto sistema de ritual nele mesmo, o muro foi "um texto, letra, caractere, reforçando as imagens vagas das divisões entre tragédias, comédias e melodrama”. Para Koolhaas, o Muro de Berlim é exemplo do conceito do "nothingness", onde há um vazio que não está realmente vazio por

\footnotetext{
${ }^{25}$ KOOLHAAS, R. El Croquis. Pg. 23.

${ }^{26}$ KOOLHAAS, R. El Croquis. Pg. 24.
} 
programar a inserção do que a fábrica excluiu no que diz respeito à mutilação da própria atividade da fábrica.

Assim, as questões pontuadas por Tafuri tornam-se cada vez mais pertinentes: O que resta do papel percorrido pela arquitetura? Até que ponto a sua inserção em tais processos transforma a própria arquitetura num simples fator econômico, e em que medida as decisões tomadas no seu âmbito específico se repercutem em estruturas mais vastas?

Em relação ao papel dos arquitetos, a descoberta do seu declínio como ideólogos ativos, a constatação das enormes possibilidades tecnológicas utilizáveis para racionalizar as cidades e os territórios, juntamente com a constatação diária da sua dissipação, o envelhecimento dos métodos específicos do projetar, mesmo antes de poder verificar as suas hipóteses na realidade, geram até hoje um clima de ansiedade que deixa entrever um panorama muito concreto e temido: "o declínio do 'profissionalismo' do arquiteto e a sua inserção, já sem obstáculos tardo-humanísticos, em programas onde o papel ideológico da arquitetura é mínimo", que acontece, segundo Tafuri, devido ao retrogradismo político de tal grupo intelectual, que revoltam-se contra as derradeiras conseqüências das promessas que contribuíram para despolitizar tentando "patéticos" relançamentos éticos da arquitetura moderna, atribuindo-Ihes "tarefas políticas que só servem para acalmar provisoriamente furores tão abstratos quanto injustificados". 27

Para Koolhaas, as mudanças na profissão de arquiteto são necessárias para que se possam enfrentar as novas condições. Em relação ao "fim do urbanismo", ele observa que o que tem acabado com o urbanismo não são os numerosos erros cometidos por inúmeros planificadores, mas o fato de que pouco dos processos e operações que tem lugar na sociedade atual pode ser traduzido a um projeto de ordenação, o produto clássico dos urbanistas. Deveríamos, segundo Koolhaas, "tentar encontrar outro produto, outra forma que resulte mais crível'. ${ }^{28}$

Enfim, analisados nos seus significados históricos reais, para Tafuri não há contradição entre construtivismo e "arte de protesto", entre racionalização da produção construtiva e subjetivismo informal ou ironia pop, entre plano capitalista e caos urbano, entre ideologia da planificação e poética do objeto. $O$ destino da cidade capitalista não é, portanto, estranho ao projeto: a ideologia do projeto mostrou-se essencial à integração do capitalismo moderno em todas as

\footnotetext{
27 TAFURI, M. Projeto e Utopia. Pg. 120.

${ }^{28}$ El Croquis. Pg 22.
} 
estruturas e superestruturas da existência humana, assim como o é a ilusão de poder opor-se a esse projeto com os instrumentos de um projeto distinto, ou de um "anteprojeto" radical.

Tafuri coloca que pode ser que a arquitetura tenha muitas tarefas específicas, mas interessa "saber porque é que até hoje a cultura de inspiração marxista nunca negou ou encobriu culposamente esta verdade: que, tal como não pode existir uma Economia política de classe, mas uma crítica de classe à Economia política, também não é possível criar uma estética, uma arte, uma arquitetura de classe, mas apenas uma crítica de classe à estética, à arte, à arquitetura, à cidade."29

De acordo com ele, a arquitetura moderna traçou as vias do seu próprio destino fazendo-se portadora de idéias de racionalização de que a classe operária só está investida em segunda instância, no âmbito de uma estratégia política autônoma devido à inevitabilidade histórica de tal fenômeno. Uma vez reconhecido como tal, já não é possível esconder a realidade última que torna inutilmente angustiantes as opções dos arquitetos desesperadamente agarrados às ideologias disciplinares: a crise descrita está, para Tafuri, ligada à própria crise da função ideológica da arquitetura.

A "queda" da arte moderna é, portanto, o último testemunho da ambigüidade burguesa, situada entre objetivos "positivos" e a desumana auto-exploração da sua redução objetiva a mercadoria sendo que, para Tafuri, não há possibilidade de salvação dentro dela: "nem vagueando, inquietos, em labirintos de imagens de tal modo polivalentes que resultam mudas, nem se fechando no árido silêncio de geometrias pagas pela sua própria perfeição."30

Por esse motivo, segundo Tafuri, não é possível propor "contra-espaços" arquitetônicos; a procura de uma alternativa inteiramente inserida nas estruturas que condicionam o próprio caráter do projeto, é uma "manifesta contradição nos termos". Para ele, a reflexão sobre a arquitetura, enquanto crítica da ideologia concreta, "realizada" pela própria arquitetura, só pode alterar-se e alcançar uma dimensão especificamente política e, só depois de excluir qualquer ideologia disciplinar, seria lícito repropor o tema dos novos papéis do técnico, do organizador da construção, do planner, no âmbito das novas formas do desenvolvimento capitalista. Para Tafuri, a crítica da ideologia hoje tem, portanto, a tarefa voltada para eliminar mitos impotentes e ineficazes, a que recorre, na maior parte das vezes, como a miragens que permitem a sobrevivência de "esperanças projetistas" anacrônicas.

Enquanto, segundo Tafuri, o Dadaísmo demonstra por absurdo a necessidade do plano ao representar o caos - confirmando sua realidade e ironizando sobre ele -, e a forma é vista, então, como oposição ao caos, ao empírico, ao cotidiano, ou seja, a tudo aquilo que

\footnotetext{
${ }^{29}$ Idem. Pg. 121.

${ }^{30}$ El Croquis. Pg. 121.
} 
concretamente torna a realidade informe, caótica, empobrecida: caos e ordem são, assim, sancionados pelas vanguardas históricas como os "valores" propriamente ditos da nova cidade capitalista. A neovanguarda, por sua vez, deveria convencer o público de que as contradições, desequilíbrios, caoticidade, típicos da cidade contemporânea, são inevitáveis, e que "o caos contém até em si riquezas inexploráveis, possibilidades ilimitadas a utilizar, valores lúdicos a propor como novos fetiches sociais". 31

Já Koolhaas vê no caos a possibilidade tanto de aceitar quanto de manipular, só que ambos até um certo ponto: Lille ${ }^{32}$ é, para ele, um exemplo de intervenção clássica que trata de minimizar o caos, enquanto em Mellun-Sénart ${ }^{33}$ o objetivo foi fazer uso dele partindo da premissa que, segundo Koolhaas, o caos é inalcançável aos arquitetos: "só podemos ser um instrumento dele, ele está fora de alcance, só podemos falar dele. O caos só se produz por erro, por acidente". ${ }^{34}$

Koolhaas define a ele e sua influência na arquitetura como sendo um conjunto de forças "quase invisíveis, incontroláveis, que de longe determinam a qualidade de um edifício, e quando muito, permitem alguma manipulação. Fenômenos triviais, mas que servem para revelar quais são as forças que estão incidindo em um ponto determinado, as forças que nesse momento nos envolvem. Não necessitamos integrá-los. São como condições atmosféricas: a integração já vem dada" ${ }^{35}$

Quanto ao produto desses processos caóticos em termos de organização formal ou material, Koolhaas diz que eles eliminam o que entendemos por composição; eliminam as conexões dentro-fora, eliminam a certeza, substituindo-a por seqüências absolutamente imprevisíveis; eliminam a coerência das oposições arquitetônicas para substituí-la pelo azar. Todas essas trocas abrem, para ele, um excitante campo para a investigação.

Enfim, "a cidade é o lugar onde as estruturas política, social e econômica são realizadas em formas desenhadas e construídas e é esta a questão social da arquitetura da cidade - como expresso no programa - que tanto interessa Rem Koolhaas" ${ }^{\text {"36 }}$, segundo define Alejandro Zaera.

O trabalho teórico de Koolhaas, estaria situado entre os pólos extremos: cidade real e Utopia, que são ambos parte do conceito da cidade. Para Koolhaas, a Utopia é caracterizada pelas intenções messiânicas modernistas; pelo arquiteto visto como herói; como forte disciplina ideológica representada com os sentidos da redenção; um novo mundo... Contudo, para ele,

\footnotetext{
31 TAFURI, M. Projeto e Utopia. Pg. 93.

${ }^{32}$ Centro Internacional de Negócios em Lille, O.M.A. França, 1988. QUADERNS Monografies. Pg. 48.

${ }^{33}$ Projeto para uma "Parisian Ville Nouvelle", Melun-Sénart, França, O.M.A. 1987. QUADERNS Monografies. Pg. 44.

34 El Croquis. Pg. 26-29.

${ }^{35}$ El Croquis. Pg. 29.

36 "Conceptual evolution of the work of Rem Koolhaas". In: QUADERNS Monografies. Pg. 54.
} 
a realidade da cidade moderna encontra em si mesma o pólo oposto da Utopia: nela não há intenções heróicas, os pensamentos positivistas e a redução ao programático caracteriza, para ele, um "procedimento de saque" de qualquer valor representacional ideológico e de sentidos secundários que o edifício possa ter. As esperanças da utopia moderna de início dos arquitetos são, assim, transformadas pela realidade de produção do capitalismo tardio.

Para "lutar" contra esses dois pólos opostos, Koolhaas utiliza, então, segundo Zaera, duas estratégias: a "subjetividade experiencial"37, através da reintrodução do desejo em toda a realidade como forma de escapar ao convencional e "puramente descritivo" planejamento urbano; e a ironia como técnica, justamente por ser "vazia de convicções filosóficas e aberta a aplicações por quase toda ideologia". ${ }^{38}$

A cultura de massa é, a partir de então, uma condição aceita, pois não há mais a ansiedade modernista do sujeito causada pela brecha resultante da mudança do uso e do valor do objeto na sociedade da reprodução em massa - como representado pela crítica marxista. No trabalho de Koohaas, a cultura de massa é assim exaltada, criando uma "euforia estática" na condição do capitalismo. Essa cultura de massa é a "cultura da congestão", que encontra sua realização na Metrópole dos anos 1930, e que permite a existência de realidades alternativas e a sobreposição de significados.

O consumo da ética, explicitado através da abertura da ética arquitetônica em direção à condição da cultura de massa, que valida o ponto de vista do consumo não é - a partir das interpretações das análises da ideologia urbana moderna realizada por Tafuri - algo totalmente novo: a ideologia do público, descrita por Tafuri como sendo o momento da ideologia em que a cidade é vista como unidade produtiva em sentido próprio e simultaneamente como instrumento de coordenação do ciclo de produção-distribuiçãoconsumo está, naquele momento para ele, ainda por nascer e, por este motivo, a ideologia do consumo deveria, assim, aparecer ao público como ideologia da correta utilização da cidade.

Contudo, no caso da cidade moderna, o intuito da planificação e reorganização urbana como meio de criar um novo sujeito do consumo e facilitar tanto a sua circulação, como deslocamento de mercadorias pela cidade - aumentando as áreas de exposição de mercadorias e das circulações - era criar algo que não existia, ao contrário da "cultura de congestão" assinalada por Koolhaas, que é uma aceitação da condição existente na tentativa

${ }^{37}$ A subjetividade experiencial, segundo Zaera, vê o edifício ou a cidade como um evento, como um contínuo de acontecimentos ou situações onde a experiência é valorizada e o sujeito, redescoberto.

${ }^{38}$ QUADERNS Monografies. Pg. 56. 
de, através dela, reintroduzir o desejo e explicitar a existência das realidades alternativas e da sobreposição de significados já citadas.

Além disso, a condição de cultura de massa - através do uso da mídia de massa, parece ter apagado a bem definida diferença antes existente entre alta e baixa cultura: segundo Tafuri, a rica classe "fetichiza" objetos que agora são metaforizados na cultura popular como resultado de um processo através do qual aquilo que a chamada "elite" elege como sendo bom é idealizado pela maioria como meio de alcance de uma imagem melhor perante toda a sociedade.

Quanto ao "envelhecimento dos métodos específicos do projetar", citados por Tafuri, Koolhaas coloca que a formação como representada pela imaginação da mídia de massa advertências, representação jornalística dos eventos em títulos, como superfície - cria uma realidade alternativa que é, segundo ele, uma nova "não-realidade" e que, por isso, precisa de novos métodos representativos: o plano convencional, secção, elevação e maquetes não são mais apropriados. Os diagramas parecem ser, para Koolhaas, o único método suficientemente representacional para uma arquitetura de performance, visto que é representativo das atividades de um organismo vivo, que a forma como ele vê a cidade.

Ainda que distantes conceitualmente, é possível refletir sobre a confluência das questões levantadas por Tafuri, Koolhaas e Jameson, entre outros, com as colocações expressas no famoso texto "Construir, Habitar, Pensar" de Heidegger, que questiona a atitude de simplesmente entender as conclusões a que a arquitetura chegou, chega e ainda chegará. Conclusões com o tempo descartadas, modelos generalizáveis que não funcionam, métodos de projetar ultrapassados a toda e qualquer mudança da estrutura econômico-social local ou global. Talvez só entender tais conclusões não baste.

E é por isso mesmo, como Dilnot afirma, que as conclusões não podem ser ensinadas: a condição moderna de pensar a arquitetura a torna, por exemplo, impossível - e ao mesmo tempo inútil - de ser ensinada, como podemos perceber, assim como a presença de tantos termos criados, citados e teoricamente compreendidos, pode bloquear a consciência sobre 0 que 0 ato de construir significa em si e o que o trabalho de arquitetura faz. A arquitetura separada do habitar, por exemplo, perde todo o seu sentido. E o que é o habitar? Há a possibilidade de uma arquitetura que mobilize as citadas esferas do "construir, habitar, pensar"? A arquitetura moderna, por exemplo, tem ordenado o caos da cidade industrial como preocupação combinada à de resolver o problema da habitação. Ou seja, é com a solução do problema habitacional que a cidade é ordenada como um todo. Acontece que, a partir desse 
momento, ela entra em crise, pois separa o homem da construção: cria uma não-identidade, uma autonomização entre as esferas "construir, habitar, pensar" que é, como podemos verificar, perdida para sempre desde então. A arquitetura, portanto, ao ser pensada como tal e separada da noção inicial do "habitar" gera suas próprias contradições, transforma-se em mercadoria.

Sua impossibilidade de prática, talvez, esteja exatamente na sua situação fora da consciência de quem a realiza: a arquitetura torna-se, assim, prática sem pensamento, incapaz de se autodescrever justamente por não mais revelar o entendimento do seu significado de sua configuração e trabalho de construção.

Tafuri coloca que, "através da semiologia, a arquitetura vai a busca do seu significado, com o pressentimento de ter perdido todo e qualquer significado, resultando em uma ulterior contradição: uma arquitetura que tenha aceitado a redução dos seus próprios elementos a signo puro e a construção da sua própria estrutura como conjunto de relações tautológicas, que remetem para si mesmas num máximo de "entropia negativa" - segundo a linguagem da teoria da informação - não pode dedicar-se a reconstruir significados "outros" através de técnicas de análise que partem precisamente da aplicação de teorias neopositivas". ${ }^{39}$

Devemos recontextualizar o pensamento arquitetônico no seu nível de fundação, recolocar num contexto histórico mais amplo que o que a arquitetura normalmente se atribui, ou adaptá-la ao novo contexto?

Isso reporta a uma importante e primordial decisão, que antecipa e determina inclusive a direção de todas as atitudes que serão tomadas em relação às questões levantadas sobre a arquitetura, sua relação com "construir, habitar, pensar", e seu próprio destino: o que se pretende é alcançar um modelo pronto, que significa, antes de mais nada, a busca de verdades às quais se possa apegar e, assim, alcançar uma certa "serenidade", "paz", ou "acomodação"; ou, ao contrário, o que se pretende é alcançar a própria essência e, por isso, admitir a não possibilidade de alcance dessa "serenidade", o eterno questionamento e a conseqüência desse fato, que é conviver, sempre, com a dúvida e o incerto?

Em todo caso, a necessidade da crítica - tão enfatizada por Tafuri - relaciona-se ao fato de que a oclusão da relação "construir-habitar" dá, ao "pensar", limitações em como pensar a própria arquitetura. Assim, ao invés de criar regras e ideais buscando a obtenção de modelos já prontos na construção da arquitetura, entender a "construção" em relação a esse "ser", e

\footnotetext{
${ }^{39}$ TAFURI, M. Projeto e Utopia. Pg. 109.
} 


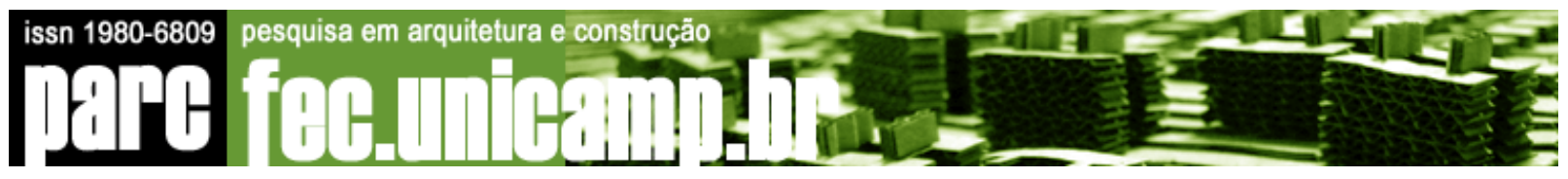

adaptá-la para ser pensada como ocasião de abertura a esta questão do "ser" ${ }^{\text {"40 }}$, parece ser o melhor caminho para alterar os atuais limites da arquitetura.
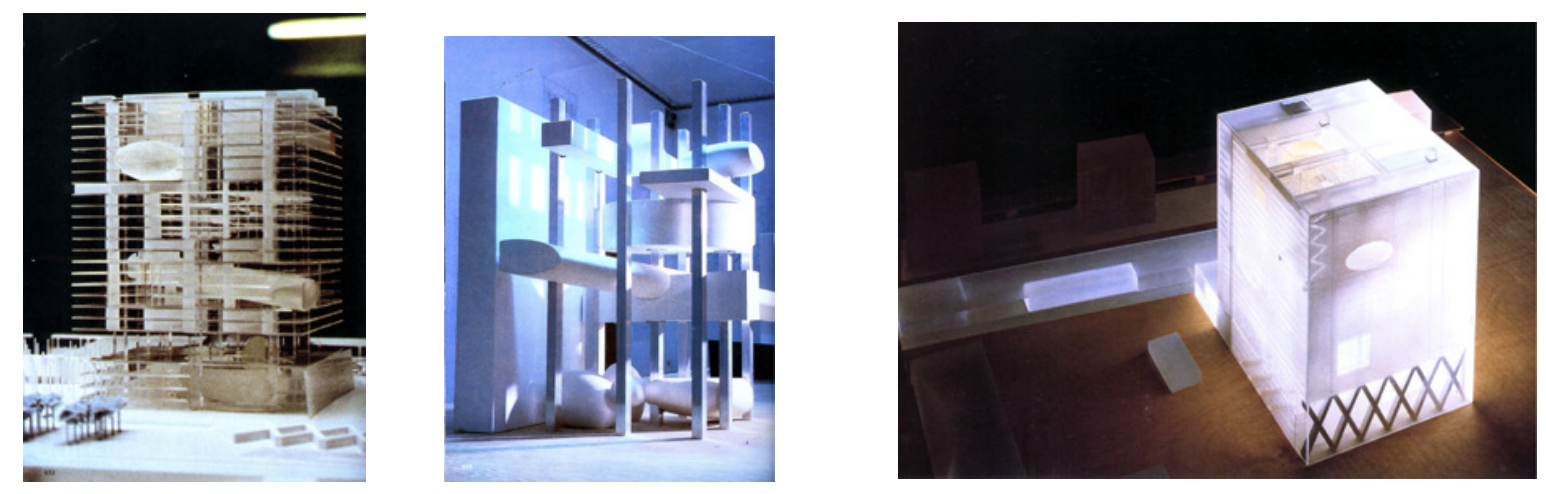

FIG. 1 - Bibliothèque de France" OMA - Office for Metropolitan Architecture . fonte: El Croquis “OMA - Rem Koolhaas 1987-1992”. Madrid, n. 53. Março 1992.

\section{Referências}

DILNOT, C. The decisive text: on beginning to read Heidegger's Building, Dwelling and Thinking.

HEIDEGGER, M. Construir, Habitar, Pensar. Barcelona. Ediciones Del Serbal, 1994.

JAMESOM, Fredric. Pós - Modernismo - A lógica cultural do capitalismo tardio. São Paulo: Ática, 1996.

JAMESOM, Fredric. Espaço e imagem: teorias do Pós - Moderno e outros ensaios. Rio de Janeiro: Editora UERJ, 1994.

JAMESOM, Fredric. A cultura do dinheiro: ensaios sobre a globalização. Petrópolis: Vozes, 2001.

JAMESOM, Fredric. Future city. In: New Left Review 21, May/June 2003. Pgs 65-79.

KOOLHAAS, R. El Croquis “OMA - Rem Koolhaas 1987-1992”. Madrid, n. 53. Março 1992.

KOOLHAAS, R.; Mau, B. Small, Medium, Large, Extra-Large: Office for Metropolitan Architecture. 1995.

\footnotetext{
${ }^{40}$ Aliás, segundo Dilnot, somente uma arquitetura que já esqueceu sua própria proposta na Terra - que é a de se relacionar com os "mortais"- pode considerar a questão "o que é ser?".
} 


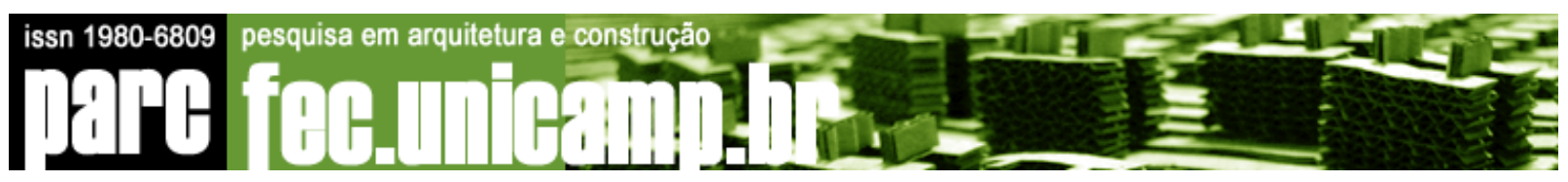

TAFURI, Manfredo. Projeto e Utopia. Lisboa: Presensa, 1986.

VELHO, Otávio Guilherme (org). O fenômeno urbano. Rio de Janeiro: Zahar Editores, 1973. QUADERNS Monografies. Rem Koolhaas: Projectes Urbans (1985-1990) / Urban Projects (1985-1990). Publicacio Del Collegi D’Arquitectes de Catalunya. Barcelona, 1990. Distribuidor: Ed. Gustavo Gili.

ZUKIN, Sharon. Aprendendo com a Disney World. Revista Espaços e Debates, v. 23 - n. 43$44-$ p. 11-27, jan/dez 2003. 